\title{
Mild balanced Intuitionistic Fuzzy Graphs
}

\author{
V. Nivethana ${ }^{1}$, A. Parvathi ${ }^{2}$ \\ ${ }^{1}$ Department of Mathematics, Sri Venkateswara Institute of Science and Technology, Thiruvallur, India \\ ${ }^{2}$ Dean, Faculty of Science, Avinashilingam University, Coimbatore, India
}

\begin{abstract}
In this paper, we introduce intense subgraphs and feeble subgraphs based on their densities and discuss mild balanced IFG and equally balanced intuitionistic fuzzy subgraphs and their properties. The operations "sum" and "union" of subgraphs of Intuitionistic Fuzzy Graphs (IFG) are analyzed. As an application of equally balanced IF subgraphs, curriculum and syllabus formation in higher educational system is discussed.

Mathematics Subject Classification: 05C72, 03E72, 03F55.

Keywords: Density of IFG, Intense subgraph, Feeble subgraph, Mild balanced IFG, Equally balanced IF subgraphs.
\end{abstract}

\section{INTRODUCTION}

The theory of fuzzy sets introduced by Zadeh in 1965 found great success and gave rise to several higher order fuzzy set. Intuitionistic fuzzy set is one among them and was introduced by Atanassov in 1986. It is a highly useful tool to deal with vagueness and finds applications in various fields such as medical sciences, life sciences, management sciences, engineering, artificial intelligence, knowledge management, networking, pattern recognition, decision making etc. In the entire application field it helps in modeling real time system where the information inherited varies with different levels of precision. In 1987, Battacharya made some remarks on fuzzy graph and, Mordeson and Nair [8], defined the concept of complement of fuzzy graph and studied some operations on fuzzy graphs. Operations on intuitionistic fuzzy graphs was studied by Parvathi, $\mathrm{R}$ et al. [12] and an extensive study was carried out by Nivethana, V et al. [11]. Akram et al. [2], introduced balanced bipolar fuzzy graphs and Karunambigai, M G et al. [7], introduced balanced intuitionistic fuzzy graphs and intuitionistic fuzzy hypergraphs. Akram et al. [1], have discussed on novel applications of intuitionistic fuzzy digraphs in decision and support system.

This paper deals with the properties of mild balanced IFG and equally balanced IF subgraphs. In section: 3 of this paper, the concept of intense subgraph, feeble subgraph and equally balanced IF subgraphs are introduced and their properties are studied. The properties of IFG under the operation "sum" and "union" as defined in [11] are analyzed. It has also been shown that an IFG with a few strong edges can never be a mild balanced IFG unless it becomes a strong IFG. In section: 4, we present application of mild balanced intuitionistic fuzzy graph in the formation of curriculum and syllabus for higher education domain, which can be adopted in universities for effective knowledge management system. By appropriate use of mild balanced IFG, balance of explicit and implicit knowledge can be ensured for the students at any stage of their learning.

\section{PRELIMINARIES}

Definition: 2.1 An intuitionistic fuzzy graph (IFG) of the form G: (V, E) said to be a Min-max IFG if

i. $\quad \mathrm{V}$ is finite non-empty set of vertices such that $\mu_{\mathrm{A}}: \mathrm{V} \rightarrow[0,1]$ and $v_{\mathrm{A}}: \mathrm{V} \rightarrow[0,1]$ denotes the degree of membership and non-membership of the elements $\mathrm{x} \in \mathrm{V}$ respectively and $0 \leq$ $\mu_{\mathrm{A}}(\mathrm{x})+v_{\mathrm{A}}(\mathrm{x}) \leq 1$ for every $\mathrm{x} \in \mathrm{V}$.

ii. $\mathrm{E} \subseteq \mathrm{V} \times \mathrm{V}$ is finite set of edges such that $\mu_{\mathrm{B}}$ : $\mathrm{V} \times \mathrm{V} \rightarrow[0,1]$ and $v_{\mathrm{B}}: \mathrm{V} \times \mathrm{V} \rightarrow[0,1]$ are such that $\mu_{\mathrm{B}}(\mathrm{xy}) \leq \min \left\{\mu_{\mathrm{A}}(\mathrm{x}), \mu_{\mathrm{A}}(\mathrm{y})\right\}$ and $v_{\mathrm{B}}(\mathrm{xy}) \leq$ $\max \left\{v_{A}(x), v_{A}(y)\right\}$ denotes the degree of membership and non-membership of the edges $(\mathrm{x}, \mathrm{y}) \in \mathrm{E}$ and $0 \leq \mu_{\mathrm{B}}(\mathrm{xy})+v_{\mathrm{B}}(\mathrm{xy}) \leq 1$ for every $(\mathrm{x}, \mathrm{y}) \in \mathrm{E}$.

Definition: 2.2 An IFG $\mathrm{H}=\left(\mathrm{V}^{\prime}, \mathrm{E}^{\prime}\right)$ is said to be an IF subgraph of $\mathrm{G}=(\mathrm{V}, \mathrm{E})$ if

i. $\quad \mathrm{V}^{\prime} \subseteq \mathrm{V}$, where $\mu_{A}^{s}(\mathrm{x})=\mu_{\mathrm{A}}(\mathrm{x}), v_{A}^{s}(\mathrm{x})=\mathrm{v}_{\mathrm{A}}(\mathrm{x})$ for all $\mathrm{x} \in \mathrm{V}^{\prime}$ and

ii. $\mathrm{E}^{\prime} \subseteq \mathrm{E}$, where $\mu_{B}^{s}(\mathrm{xy})=\mu_{\mathrm{B}}(\mathrm{xy}), v_{B}^{s}(\mathrm{xy})=$ $v_{\mathrm{B}}(\mathrm{xy})$ for all $\mathrm{xy} \in \mathrm{E}^{\prime}$.

Definition: 2.3 An IF subgraphs $H_{1}=\left(V_{1}, E_{1}\right)$ is said to be connected IF subgraph if there exist atleast one path between every pair of vertices in $\mathrm{V}_{1}$.

Definition: 2.4 An IFG is said to be strong if $\mu_{\mathrm{B}}(\mathrm{xy})=\mu_{\mathrm{A}}(\mathrm{x}) \wedge \mu_{\mathrm{A}}(\mathrm{y})$ and $v_{\mathrm{B}}(\mathrm{xy})=v_{\mathrm{A}}(\mathrm{x}) \vee v_{\mathrm{A}}(\mathrm{y})$ $\forall \mathrm{xy} \in \mathrm{E}$. 
Definition: 2.5 An $\operatorname{arc}(\mathrm{x}, \mathrm{y})$ of an IFG is strong if both $\mu_{\mathrm{B}}(\mathrm{xy})=\min \left\{\mu_{\mathrm{A}}(\mathrm{x}), \quad \mu_{\mathrm{A}}(\mathrm{y})\right\} \quad$ and $v_{\mathrm{B}}(\mathrm{xy})=\max \left\{v_{\mathrm{A}}(\mathrm{x}), v_{\mathrm{A}}(\mathrm{y})\right\}$.

Definition: 2.6 The complement of an IFG, $\mathrm{G}:(\mathrm{V}, \mathrm{E})$ is an IFG, $\overline{\mathrm{G}}:(\overline{\mathrm{V}}, \overline{\mathrm{E}})$ where

$$
\begin{array}{lll}
\text { i. } & \overline{\mathrm{V}}=\mathrm{V} \\
\text { ii. } & \bar{\mu}_{\mathrm{A}}(\mathrm{x})=\mu_{\mathrm{A}}(\mathrm{x}) ; \overline{\mathrm{v}}_{\mathrm{A}}(\mathrm{x})=v_{\mathrm{A}}(\mathrm{x}) \forall \mathrm{x} \in \mathrm{V} \\
\text { iii. } & \bar{\mu}_{\mathrm{B}}(\mathrm{xy})= \begin{cases}{\left[\mu_{\mathrm{A}}(\mathrm{x}) \wedge \mu_{\mathrm{A}}(\mathrm{y})\right]-\mu_{\mathrm{B}}(\mathrm{xy})} & \forall \mathrm{xy} \in \mathrm{E} \\
{\left[\mu_{\mathrm{A}}(\mathrm{x}) \wedge \mu_{\mathrm{A}}(\mathrm{y})\right]} & \forall \mathrm{xy} \notin \mathrm{E}\end{cases} \\
& \bar{v}_{\mathrm{B}}(\mathrm{xy})= \begin{cases}{\left[v_{\mathrm{A}}(\mathrm{x}) \vee v_{\mathrm{A}}(\mathrm{y})\right]-v_{\mathrm{B}}(\mathrm{xy})} & \forall \mathrm{xy} \in \mathrm{E} \\
{\left[v_{\mathrm{A}}(\mathrm{x}) \vee v_{\mathrm{A}}(\mathrm{y})\right]} & \forall \mathrm{xy} \notin \mathrm{E}\end{cases}
\end{array}
$$

Definition: 2.7 Let $\mathrm{G}_{1}:\left(\mathrm{V}_{1}, \mathrm{E}_{1}\right)$ and $\mathrm{G}_{2}:\left(\mathrm{V}_{2}, \mathrm{E}_{2}\right)$ be two IFGs with one or more vertices in common. Then the union of $G_{1}$ and $G_{2}$ is another IFG $\mathrm{G}:(\mathrm{V}, \mathrm{E})=\mathrm{G}_{1} \cup \mathrm{G}_{2}$ defined by,

$$
\begin{aligned}
& \mu_{\mathrm{A}}(\mathrm{x})=\left\{\begin{array}{ll}
\mu_{1 \mathrm{~A}}(\mathrm{x}) & \forall \mathrm{x} \in \mathrm{V}_{1} \\
\mu_{2 \mathrm{~A}}(\mathrm{x}) & \forall \mathrm{x} \in \mathrm{V}_{2}
\end{array} \quad\right. \text { and } \\
& v_{\mathrm{A}}(\mathrm{x})= \begin{cases}v_{1 \mathrm{~A}}(\mathrm{x}) & \forall \mathrm{x} \in \mathrm{V}_{1} \\
v_{2 \mathrm{~A}}(\mathrm{x}) & \forall \mathrm{x} \in \mathrm{V}_{2}\end{cases} \\
& \mu_{\mathrm{B}}(\mathrm{xy})=\left\{\begin{array}{ll}
\mu_{1 \mathrm{~B}}(\mathrm{xy}) & \forall \mathrm{xy} \in \mathrm{E}_{1} \\
\mu_{2 \mathrm{~B}}(\mathrm{xy}) & \forall \mathrm{xy} \in \mathrm{E}_{2}
\end{array}\right. \text { and } \\
& v_{\mathrm{B}}(\mathrm{xy})= \begin{cases}v_{1 \mathrm{~B}}(\mathrm{xy}) & \forall \mathrm{xy} \in \mathrm{E}_{1} \\
v_{2 \mathrm{~B}}(\mathrm{xy}) & \forall \mathrm{xy} \in \mathrm{E}_{2}\end{cases}
\end{aligned}
$$$$
\text { (ii) }
$$

Definition: 2.8 Let $\mathrm{G}_{1}:\left(\mathrm{V}_{1}, \mathrm{E}_{1}\right)$ and $\mathrm{G}_{2}:\left(\mathrm{V}_{2}, \mathrm{E}_{2}\right)$ be two IFGs with one or more vertices in common. Then $\mathrm{G}_{1}+\mathrm{G}_{2}$ is another IFG G: $(V, E)$ defined by,

$$
\begin{aligned}
& \mu_{\mathrm{A}}(\mathrm{x})=\left\{\begin{array}{ll}
\mu_{1 \mathrm{~A}}(\mathrm{x}) & \forall \mathrm{x} \in \mathrm{V}_{1} \\
\mu_{2 \mathrm{~A}}(\mathrm{x}) & \forall \mathrm{x} \in \mathrm{V}_{2}
\end{array} \quad\right. \text { and } \\
& v_{\mathrm{A}}(\mathrm{x})= \begin{cases}v_{1 \mathrm{~A}}(\mathrm{x}) & \forall \mathrm{x} \in \mathrm{V}_{1} \\
v_{2 \mathrm{~A}}(\mathrm{x}) & \forall \mathrm{x} \in \mathrm{V}_{2}\end{cases} \\
& \mu_{\mathrm{B}}(\mathrm{xy})=\left\{\begin{array}{ll}
\mu_{1 \mathrm{~B}}(\mathrm{xy}) & \forall \mathrm{xy} \in \mathrm{E}_{1} \\
\mu_{2 \mathrm{~B}}(\mathrm{xy}) & \forall \mathrm{xy} \in \mathrm{E}_{2}
\end{array}\right. \text { and } \\
& v_{\mathrm{B}}(\mathrm{xy})= \begin{cases}v_{1 \mathrm{~B}}(\mathrm{xy}) & \forall \mathrm{xy} \in \mathrm{E}_{1} \\
v_{2 \mathrm{~B}}(\mathrm{xy}) & \forall \mathrm{xy} \in \mathrm{E}_{2}\end{cases}
\end{aligned}
$$

There exists a strong edge between every pair of non-common vertices in $\mathrm{G}_{1}$ and $\mathrm{G}_{2}$.

Definition : 2.9 The density of an intuitionistic fuzzy graph $G:(V, E)$ is $D(G)=\left(D_{\mu}(G), D_{v}(G)\right)$ where $D_{\mu}(G)$ and $D_{v}(G)$ are defined by

$$
\begin{aligned}
& \mathrm{D}_{\mu}(\mathrm{G})=\frac{\sum_{\forall v_{i}, v_{j} \in \mathrm{V}} \mu_{B}\left(v_{i} v_{j}\right)}{\sum_{\forall v_{i} \in v_{j} \in E}\left(\mu_{A}\left(v_{i}\right) \wedge \mu_{A}\left(v_{j}\right)\right)} \text { and } \\
& \mathrm{D}_{v}(\mathrm{G})=\frac{2 \forall v_{i}, v_{j} \in \mathrm{V} v_{B}\left(v_{i} v_{j}\right)}{\sum_{\forall v_{i} v_{j} \in E}\left(v_{A}\left(v_{i}\right) \vee v_{A}\left(v_{j}\right)\right)} .
\end{aligned}
$$

\section{MILD BALANCED INTUITIONISTIC FUZZY GRAPHS}

Definition: 3.1 A connected subgraph $\mathrm{H}$ of an intuitionistic fuzzy graph $\mathrm{G}$ : $(\mathrm{V}, \mathrm{E})$ is called Intense subgraph if (i). $\mathrm{V}(\mathrm{H}) \subseteq \mathrm{V}(\mathrm{G})$ and $\mathrm{E}(\mathrm{H}) \subseteq \mathrm{E}(\mathrm{G})$,

(ii). $D_{\mu}(H) \leq D_{\mu}(G)$ and $D_{v}(H) \leq D_{v}(G)$.

Definition: 3.2 A connected subgraph $\mathrm{H}$ of an intuitionistic fuzzy graph $\mathrm{G}$ : $(\mathrm{V}, \mathrm{E})$ is called Feeble subgraph if (i) $\mathrm{V}(\mathrm{H}) \subseteq \mathrm{V}(\mathrm{G})$ and $\mathrm{E}(\mathrm{H}) \subseteq \mathrm{E}(\mathrm{G})$ and (ii) $D_{\mu}(H)>D_{\mu}(G)$ and $D_{v}(H)>D_{v}(G)$.

Example: 3.3 Consider an IFG G:(V,E) with

\begin{tabular}{|c|c|c|c|c|c|c|c|c|c|c|c|c|}
\hline $\begin{array}{l}\text { Sub } \\
\text { graphs }\end{array}$ & $\begin{array}{l}\text { Vertex } \\
\text { set: V }\end{array}$ & $\begin{array}{l}\text { Edge } \\
\text { set: }\end{array}$ & & (H) & $\mathrm{Dv}(\mathrm{H})$ & $\begin{array}{l}\text { Sub } \\
\text { graphs }\end{array}$ & $\begin{array}{l}\text { Vertex } \\
\text { set: V }\end{array}$ & Edge set: $E$ & \multicolumn{2}{|c|}{$\mathrm{D}_{\mu}(\mathrm{H})$} & \multicolumn{2}{|c|}{$\mathrm{Dv}(\mathrm{H})$} \\
\hline \multirow{2}{*}{$\mathrm{H}_{1}$} & \multirow{2}{*}{$a, b$} & \multirow{2}{*}{$a b$} & 0.8 & \multirow{2}{*}{$=1.82$} & 0.6 & \multirow{2}{*}{$\mathrm{H}_{11}$} & \multirow{2}{*}{$\mathrm{a}, \mathrm{b}, \mathrm{c}, \mathrm{d}$} & \multirow{2}{*}{$\mathrm{ab}, \mathrm{bc}, \mathrm{cd}$} & 2.76 & \multirow{2}{*}{$=1.85$} & 1.8 & \multirow{2}{*}{$=1.64$} \\
\hline & & & 0.44 & & $=1.5$ & & & & 1.49 & & 1.1 & \\
\hline \multirow{2}{*}{$\mathrm{H}_{2}$} & \multirow{2}{*}{$b, c$} & \multirow{2}{*}{$b c$} & 0.96 & \multirow{2}{*}{$=1.92$} & \multirow{2}{*}{$=2$} & \multirow{2}{*}{$\mathrm{H}_{12}$} & \multirow{2}{*}{$\mathrm{a}, \mathrm{b}, \mathrm{c}, \mathrm{e}$} & \multirow{2}{*}{$e a, a b, b c$} & 2.64 & \multirow{2}{*}{$=1.91$} & 2 & \multirow{2}{*}{$=1.72$} \\
\hline & & & 0.5 & & & & & & 1.38 & & 1.16 & \\
\hline \multirow{2}{*}{$\mathrm{H}_{3}$} & \multirow{2}{*}{$c, d$} & \multirow{2}{*}{$c d$} & 1 & \multirow{2}{*}{$=1.82$} & \multirow{2}{*}{$=1.3$} & \multirow{2}{*}{$\mathrm{H}_{13}$} & \multirow{2}{*}{$\mathrm{a}, \mathrm{b}, \mathrm{d}, \mathrm{e}$} & \multirow{2}{*}{$\mathrm{de}, \mathrm{ea}, \mathrm{ab}$} & 2.58 & \multirow{2}{*}{$=1.8$} & 1.5 & \multirow{2}{*}{$=1.48$} \\
\hline & & & 0.55 & & & & & & 1.43 & & 1.01 & \\
\hline
\end{tabular}
$\mathrm{V}=\{\mathrm{a}, \mathrm{b}, \mathrm{c}, \mathrm{d}, \mathrm{e}\}$ and $\mathrm{E}=\{\mathrm{ab}, \mathrm{bc}, \mathrm{cd}, \mathrm{de}, \mathrm{ea}\}$.

The $\mu$-density and $v$-density of the graph are as follows.

$D_{\mu}(G)=\frac{2(0.4+0.48+0.5+0.45+0.45)}{0.44+0.5+0.55+0.55+0.44}=\frac{4.56}{2.48}=1.84$

and $D_{v}(G)=\frac{2(0.3+0.4+0.2+0.15+0.3)}{0.4+0.4+0.3+0.25+0.36}=\frac{2.7}{1.71}=1.58$.

Hence, $D(G)=(1.84,1.58)$.

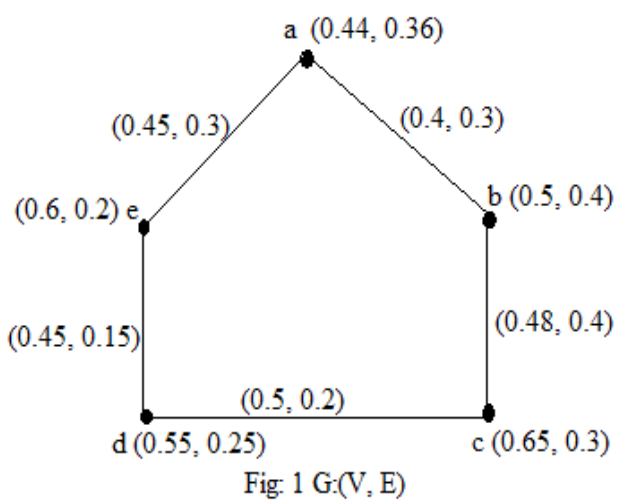

All the possible connected subgraphs of the above graph G:(V,E) in Fig:1 are tabulated and their $\mu$-density and $\nu$-density are calculated (rounded to two decimal places) in the Table: 3.1 below. From the table it can be observed that

$\left\{\mathrm{H}_{1}, \mathrm{H}_{3}, \mathrm{H}_{4}, \mathrm{H}_{8}, \mathrm{H}_{9}, \mathrm{H}_{13}, \mathrm{H}_{14}, \mathrm{H}_{15}, \mathrm{H}_{17}, \mathrm{H}_{20}\right\}$ are intense subgraphs and

$\left\{\mathrm{H}_{2}, \mathrm{H}_{5}, \mathrm{H}_{6}, \mathrm{H}_{7}, \mathrm{H}_{10}, \mathrm{H}_{11}, \mathrm{H}_{12}, \mathrm{H}_{16}, \mathrm{H}_{18}, \mathrm{H}_{19}\right\}$ are feeble subgraphs. 


\begin{tabular}{|c|c|c|c|c|c|c|c|c|c|c|c|c|c|}
\hline \multirow{2}{*}{$\mathrm{H}_{4}$} & \multirow{2}{*}{$\mathrm{d}, \mathrm{e}$} & \multirow{2}{*}{$\mathrm{de}$} & 0.9 & \multirow{2}{*}{$=1.64$} & 0.3 & \multirow{2}{*}{$=1.2$} & \multirow{2}{*}{$\mathrm{H}_{14}$} & \multirow{2}{*}{$\mathrm{a}, \mathrm{c}, \mathrm{d}, \mathrm{e}$} & \multirow{2}{*}{$\mathrm{cd}, \mathrm{de}, \mathrm{ea}$} & 2.78 & \multirow{2}{*}{$=1.81$} & 1.3 & \multirow{2}{*}{$=1.44$} \\
\hline & & & 0.55 & & 0.3 & & & & & 1.54 & & 0.91 & \\
\hline \multirow{2}{*}{$\mathrm{H}_{5}$} & \multirow{2}{*}{$e, a$} & \multirow{2}{*}{$e a$} & 0.88 & \multirow{2}{*}{$=2$} & 0.6 & \multirow{2}{*}{$=1.7$} & \multirow{2}{*}{$\mathrm{H}_{15}$} & \multirow{2}{*}{$b, c, d, e$} & \multirow{2}{*}{$\mathrm{bc}, \mathrm{cd}, \mathrm{de}$} & 2.86 & \multirow{2}{*}{$=1.79$} & 1.5 & \multirow{2}{*}{$=1.57$} \\
\hline & & & 0.44 & & 0.4 & & & & & 1.6 & & 0.95 & \\
\hline \multirow{2}{*}{$\mathrm{H}_{6}$} & \multirow{2}{*}{$a, b, c$} & \multirow{2}{*}{$a b, b c$} & 1.76 & \multirow{2}{*}{$=1.87$} & 1.4 & \multirow{2}{*}{$=1.8$} & \multirow{2}{*}{$\mathrm{H}_{16}$} & \multirow{2}{*}{$a, b, c, d, e$} & \multirow{2}{*}{$\mathrm{bc}, \mathrm{cd}, \mathrm{de}, \mathrm{ea}$} & 3.74 & \multirow{2}{*}{$=1.83$} & 2.1 & \multirow{2}{*}{$=1.6$} \\
\hline & & & 0.94 & & 0.8 & & & & & 2.09 & & 1.31 & \\
\hline \multirow{2}{*}{$\mathrm{H}_{7}$} & \multirow{2}{*}{$b, c, d$} & \multirow{2}{*}{$\mathrm{bc}, \mathrm{cd}$} & 1.96 & \multirow{2}{*}{$=1.87$} & 1.2 & \multirow{2}{*}{$=1.7$} & $\mathrm{H}$ & $5 \mathrm{ab} \mathrm{cd}^{-3}$ & Soboddees & 3.58 & -181 & 1.9 & $-1,44$ \\
\hline & & & 1.05 & & 0.7 & & 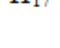 & $(4,0,0,4,2)$ & {$[40,0,0,0,2)$} & 1.98 & & 1.32 & \\
\hline & & & 1.9 & & 0.7 & & & & & 3.54 & & 2.3 & \\
\hline $\mathrm{H}_{8}$ & $\{c, d, e\}$ & $\{c d, d e\}$ & 1.1 & $=1.13$ & 0.6 & $=1.3$ & $\mathrm{H}_{18}$ & $\{a, b, c, d, e\}$ & $\{\mathrm{ab}, \mathrm{bc}, \mathrm{de}, \mathrm{ea}\}$ & 1.93 & $=1.83$ & 1.41 & $=1.03$ \\
\hline $\mathrm{H}_{9}$ & $\{d, e, a\}$ & $\{\mathrm{de}, \mathrm{ea}\}$ & 1.78 & $=1.8$ & 0.9 & $=1.5$ & $\mathrm{H}_{10}$ & $\{\mathrm{a}, \mathrm{b}, \mathrm{c}, \mathrm{d}, \mathrm{e}\}$ & $\{a b, b c, c d, e a\}$ & 3.64 & $=1.89$ & 2.4 & $=1.64$ \\
\hline & & & 0.99 & & 0.6 & & & & & 1.93 & & 1.46 & \\
\hline & & & 1.68 & & 1.2 & & & & & 3.66 & & 2.1 & 157 \\
\hline 1110 & $\{c, a, 0\}$ & $20, a, d\}$ & 0.88 & -1.51 & 0.8 & -1.0 & $11_{20}$ & $\{a, 0, c, a,-\}$ & $\{\mathrm{a} 0,0 \mathrm{C}, \mathrm{CU}, \mathrm{de}\}$ & 2.04 & -1.79 & 1.34 & -1.51 \\
\hline
\end{tabular}

Table: 3.1

Definition: 3.4 An intuitionistic fuzzy graph G: $(V, E)$ is mild balanced IFG if all connected subgraphs of $\mathrm{G}$ are intense subgraphs.

Definition: 3.5 Two intense intuitionistic fuzzy connected subgraphs $\mathrm{H}_{1}$ and $\mathrm{H}_{2}$ of an IFG G: (V, E) are called equally balanced subgraphs if

(i) $\mathrm{D}_{\mu}\left(\mathrm{H}_{1}\right) \leq \mathrm{D}_{\mu}(\mathrm{G})$ and $\mathrm{D}_{\mu}\left(\mathrm{H}_{2}\right) \leq \mathrm{D}_{\mu}(\mathrm{G})$

(ii) $\mathrm{D}_{v}\left(\mathrm{H}_{1}\right) \leq \mathrm{D}_{v}(\mathrm{G})$ and $\mathrm{D}_{v}\left(\mathrm{H}_{2}\right) \leq \mathrm{D}_{v}(\mathrm{G})$

(iii) $\mathrm{D}_{\mu}\left(\mathrm{H}_{1}\right)=\mathrm{D}_{\mu}\left(\mathrm{H}_{2}\right)$ and $\mathrm{D}_{v}\left(\mathrm{H}_{1}\right)=\mathrm{D}_{v}\left(\mathrm{H}_{2}\right)$

In the above example: $3.3, \mathrm{H}_{14}$ and $\mathrm{H}_{17}$ are equally balanced intuitionistic fuzzy subgraphs. Similarly $\mathrm{H}_{15}$ and $\mathrm{H}_{20}$ are also equally balanced intuitionistic fuzzy subgraphs in pairs.

Definition: 3.6 If $\mathrm{D}_{\mu}\left(\mathrm{H}_{\mathrm{i}}\right)=\mathrm{D}_{\mu}(\mathrm{G})$ and $\mathrm{D}_{v}\left(\mathrm{H}_{\mathrm{i}}\right)=$ $D_{v}(G)$ for all possible connected subgraphs $H_{i}$ of $G$, then the graph G: $(V, E)$ is called a strictly balanced intuitionistic fuzzy graph.

Example: 3.7 Consider an IFG G:(V, E) where $\mathrm{V}=\{1,2,3,4\}$ and $\mathrm{E}=\{12,23,34,41\}$ with membership and non-membership values as given below.

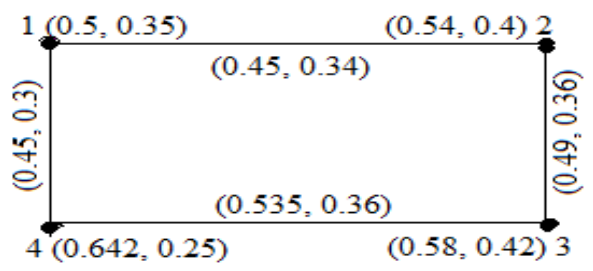

Fig: 2 G:(V, E)

In this graph $\mathrm{D}(\mathrm{G})=(1.8,1.7)$. All possible connected subgraph are $\mathrm{H}_{1}=\{12\}, \mathrm{H}_{2}=\{23\}$, $\mathrm{H}_{3}=\{34\}, \quad \mathrm{H}_{4}=\{14\}, \quad \mathrm{H}_{5}=\{12,23\}, \quad \mathrm{H}_{6}=\{12,14\}$, $\mathrm{H}_{7}=\{23,34\}, \quad \mathrm{H}_{8}=\{34,14\}, \quad \mathrm{H}_{9}=\{12,23,34\}$, $\mathrm{H}_{10}=\{12,23,14\}, \mathrm{H}_{11}=\{12,34,41\}, \mathrm{H}_{12}=\{23,34,41\}$.
The density of all the above subgraphs are $\mathrm{D}\left(\mathrm{H}_{\mathrm{i}}\right)=(1.8,1.7) \forall \mathrm{i}=1$ to 12 . Hence the above graph becomes strictly balanced intuitionistic fuzzy graph.

Proposition: 3.8 For a strong IFG, D $(G)=(2,2)$ and it is strictly balanced.

Proof: Since all the edges of G: $(\mathrm{V}, \mathrm{E})$ are strong

$\mu_{\mathrm{B}}\left(\mathrm{v}_{\mathrm{i}} \mathrm{v}_{\mathrm{j}}\right)=\mu_{\mathrm{A}}\left(\mathrm{v}_{\mathrm{i}}\right) \wedge \mu_{\mathrm{A}}\left(\mathrm{v}_{\mathrm{j}}\right)$ and

$v_{\mathrm{B}}\left(\mathrm{v}_{\mathrm{i}} \mathrm{v}_{\mathrm{j}}\right)=v_{\mathrm{A}}\left(\mathrm{v}_{\mathrm{i}}\right) \vee v_{\mathrm{A}}\left(\mathrm{v}_{\mathrm{j}}\right)$.

By def,

$\mathrm{D}_{\mu}(\mathrm{G})=\frac{2 \sum \mu_{B}\left(v_{i} v_{j}\right)}{\sum \mu_{A}\left(v_{i}\right) \wedge \mu_{A}\left(v_{j}\right)}=\frac{2 \sum \mu_{A}\left(v_{i}\right) \wedge \mu_{A}\left(v_{j}\right)}{\sum \mu_{A}\left(v_{i}\right) \wedge \mu_{A}\left(v_{j}\right)}=2$,
$\mathrm{D}_{v}(\mathrm{G})=\frac{2 \sum v_{B}\left(v_{i} v_{j}\right)}{\sum v_{A}\left(v_{i}\right) \vee v_{A}\left(v_{j}\right)}=\frac{2 \sum v_{A}\left(v_{i}\right) \vee v_{A}\left(v_{j}\right)}{\sum v_{A}\left(v_{i}\right) \vee v_{A}\left(v_{j}\right)}=2$.

Hence $D(G)=\left(D_{\mu}(G), D_{v}(G)\right)=(2,2)$. Also all the connected subgraphs of G: $(\mathrm{V}, \mathrm{E})$ has strong edges and hence $\mathrm{D}(\mathrm{H})=(2,2)$ for all subgraphs $\mathrm{H}$ of $\mathrm{G}$. Hence G: (V, E) is strictly balanced.

Corollary: 3.9 An IFG with a few strong edges can never be a mild balanced IFG.

Proof: If an IFG has one or a few strong edges (not all), then for the connected subgraph $\mathrm{H}$ which has only strong edges, $D_{\mu}(H)=2$ and $D_{v}(H)=2$. Hence $\mathrm{D}(\mathrm{H})=(2,2)>\mathrm{D}(\mathrm{G})$. Hence it can't be a mild balanced IFG.

Remark It can be noted that subgraphs with strong edges are always feeble subgraphs of an IFG unless it is a strong IFG.

Proposition: 3.10 Union of two equally balanced connected IF subgraphs, with one or more vertices in common are also equally balanced

Proof: Let $\mathrm{H}_{1}$ and $\mathrm{H}_{2}$ be two equally balanced connected IF subgraphs with atleast one common vertex of an IFG, G:(V, E). By definition 
$\mathrm{D}\left(\mathrm{H}_{1}\right)=\mathrm{D}\left(\mathrm{H}_{2}\right) \leq \mathrm{D}(\mathrm{G})$.

$\mathrm{D}_{\mu}\left(\mathrm{H}_{1}\right)=\frac{2 \forall v_{i}, v_{j} \in V\left(H_{1}\right)}{\mu_{B}\left(v_{i} v_{j}\right)}=\frac{2 a}{b}$ and

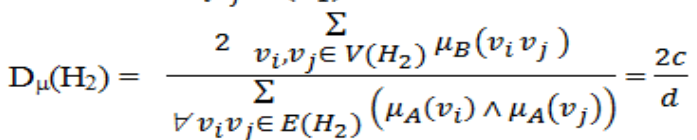

Since $\mathrm{D}_{\mu}\left(\mathrm{H}_{1}\right)=\mathrm{D}_{\mu}\left(\mathrm{H}_{2}\right) \Rightarrow \frac{a}{b}=\frac{c}{d} \Rightarrow \frac{c}{d}=\frac{K(a)}{K(b)}$.

$\therefore \mathrm{D}_{\mu}\left(\mathrm{H}_{1}\right)=\mathrm{D}_{\mu}\left(\mathrm{H}_{2}\right)=\frac{2 a}{b}$

$\mathrm{D}_{\mu}\left(\mathrm{H}_{1} \cup \mathrm{H}_{2}\right)=$

$\frac{2\left[\sum_{v_{i}, v_{j} \in V\left(H_{1}\right)} \mu_{B}\left(v_{i} v_{j}\right)+{ }_{v_{i}, v_{j} \in V\left(H_{2}\right)} \mu_{B}\left(v_{i} v_{j}\right)\right]}{\sum_{\forall v_{i} v_{j} \in E\left(H_{1}\right)}\left(\mu_{A}\left(v_{i}\right) \wedge \mu_{A}\left(v_{j}\right)\right)+\sum_{\forall v_{i} v_{j} \in E\left(H_{2}\right)}\left(\mu_{A}\left(v_{i}\right) \wedge \mu_{A}\left(v_{j}\right)\right)}$

$=\frac{2[a+c]}{b+d}=\frac{2(a+k a)}{b+k b}=\frac{2 a(k+1)}{b(k+1)}$

$\therefore \mathrm{D}_{\mu}\left(\mathrm{H}_{1} \cup \mathrm{H}_{2}\right)=\frac{2 a}{b}$

Hence $\mathrm{D}_{\mu}\left(\mathrm{H}_{1} \cup \mathrm{H}_{2}\right)=\mathrm{D}_{\mu}\left(\mathrm{H}_{1}\right)=\mathrm{D}_{\mu}\left(\mathrm{H}_{2}\right)$.

Similarly it can be shown that

$\mathrm{D}_{v}\left(\mathrm{H}_{1} \mathrm{U}_{\mathrm{H}_{2}}\right)=\mathrm{D}_{\mathrm{v}}\left(\mathrm{H}_{1}\right)=\mathrm{D}_{\mathrm{v}}\left(\mathrm{H}_{2}\right)$.

$\therefore \mathrm{D}\left(\mathrm{H}_{1} \mathrm{UH}_{2}\right)=\mathrm{D}\left(\mathrm{H}_{1}\right)=\mathrm{D}\left(\mathrm{H}_{2}\right)$.

Corollary: 3.11 If all the possible connected subgraphs of a mild balanced IFG are equally balanced then the graph in turn is strictly balanced IFG.

Proof: This can be proved by decomposing the graph into two connected subgraphs which are equally balanced. From the above proposition it follows that the union of two equally balanced connected IF subgraphs is equally balanced, the graph itself becomes a strictly balanced IFG.

Proposition: 3.12 Two connected IFG's $\mathrm{G}_{1}$ and $\mathrm{G}_{2}$ with atleast one common vertex are intense subgraphs of IFG $\mathrm{G}_{1}+\mathrm{G}_{2}$.

Proof: Let $\mathrm{G}_{1}:\left(\mathrm{V}_{1}, \mathrm{E}_{1}\right)$ and $\mathrm{G}_{2}:\left(\mathrm{V}_{2}, \mathrm{E}_{2}\right)$ be two connected IFG's with atleast one common vertex.

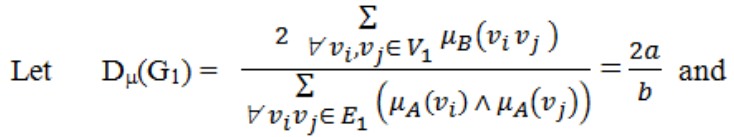

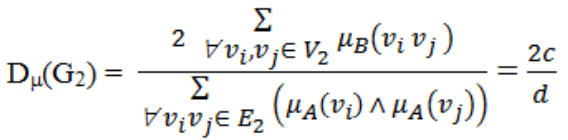

$$
\begin{aligned}
& \mathrm{D}_{\mu}\left(\mathrm{G}_{1}+\mathrm{G}_{2}\right)=
\end{aligned}
$$

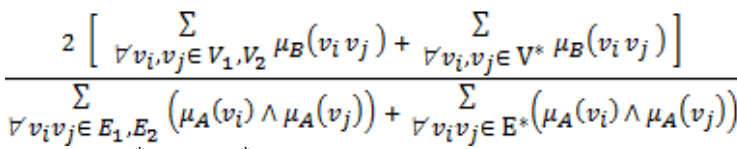

Where $\mathrm{V}^{*}$ and $\mathrm{E}^{*}$ are the set of vertices and strong edges between every pair of non-common vertices of $G_{1}$ and $G_{2}$. Obviously $\mu_{B}\left(v_{i} v_{j}\right)=\mu_{A}\left(v_{i}\right) \wedge \mu_{A}\left(v_{j}\right)$ for all $\mathrm{v}_{\mathrm{i}} \mathrm{v}_{\mathrm{j}} \in \mathrm{E}^{*}$, since we add a strong edge between all pairs of non- common vertices of $\mathrm{G}_{1}$ and $\mathrm{G}_{2}$. (ie) $\sum \mu_{B}\left(v_{i} v_{j}\right)=\sum \mu_{A}\left(v_{i}\right) \wedge \mu_{A}\left(v_{j}\right) \forall \mathrm{v}_{\mathrm{i}} \mathrm{v}_{\mathrm{j}} \in \mathrm{E}^{*}$,

$\mathrm{D}_{\mu}\left(\mathrm{G}_{1}+\mathrm{G}_{2}\right)=\frac{2(a+c+x)}{b+d+x}>\frac{2 a}{b}>\frac{2 c}{d}$

$\therefore \mathrm{D}_{\mu}\left(\mathrm{G}_{1}+\mathrm{G}_{2}\right)>\mathrm{D}_{\mu}\left(\mathrm{G}_{1}\right)$ and $\mathrm{D}_{\mu}\left(\mathrm{G}_{1}+\mathrm{G}_{2}\right)>\mathrm{D}_{\mu}\left(\mathrm{G}_{2}\right)$.

Similarly it can be shown that

$\mathrm{D}_{v}\left(\mathrm{G}_{1}\right)<\mathrm{D}_{v}\left(\mathrm{G}_{1}+\mathrm{G}_{2}\right)$ and $\mathrm{D}_{v}\left(\mathrm{G}_{2}\right)<\mathrm{D}_{v}\left(\mathrm{G}_{1}+\mathrm{G}_{2}\right)$.

$\therefore \mathrm{D}\left(\mathrm{G}_{1}\right)<\mathrm{D}\left(\mathrm{G}_{1}+\mathrm{G}_{2}\right)$ and $\mathrm{D}\left(\mathrm{G}_{2}\right)<\mathrm{D}\left(\mathrm{G}_{1}+\mathrm{G}_{2}\right)$.

Hence $G_{1}$ and $G_{2}$ are intense subgraphs of $G_{1}+G_{2}$. In particular, $\mathrm{D}\left(\mathrm{G}_{1}\right)=\mathrm{D}\left(\mathrm{G}_{1}+\mathrm{G}_{2}\right)=\mathrm{D}\left(\mathrm{G}_{2}\right)$ if all the graphs are strong IFG's.

Proposition: 3.13 Two connected IFG's $G_{1}$ and $G_{2}$ with atleast one common vertex are not intense subgraphs of their union.

Example: 3.14 Consider the following IFG $G_{1}:\left(A_{1}, B_{1}\right)$ and $G_{2}:\left(A_{2}, B_{2}\right)$ and their union $G_{1} \cup G_{2}$

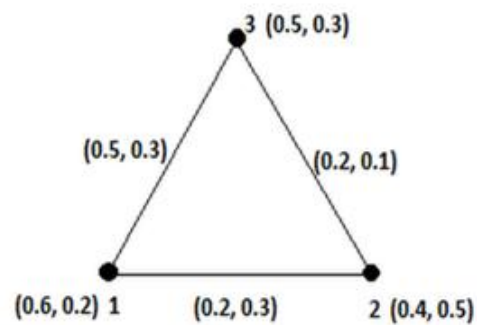

Fig: $3 \mathrm{G}_{1}:\left(\mathrm{A}_{1}, \mathrm{~B}_{1}\right)$

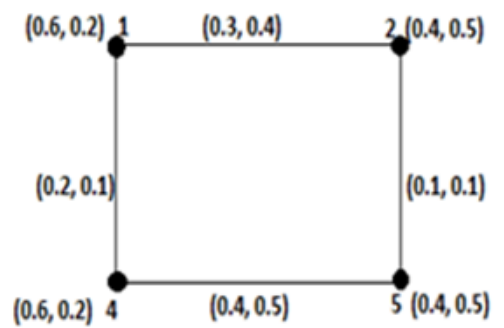

Fig: $4 \mathrm{G}_{2}:\left(\mathrm{A}_{2}, \mathrm{~B}_{2}\right)$

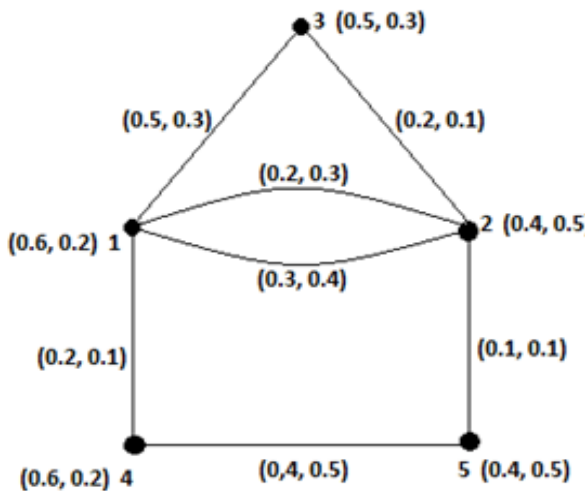

Fig: $5 \quad \mathrm{G}_{1} \cup \mathrm{G}_{2}$

In these graphs $\mathrm{D}\left(\mathrm{G}_{1}\right)=1.38, \mathrm{D}\left(\mathrm{G}_{2}\right)=1.11$ and $\mathrm{D}\left(\mathrm{G}_{1} \cup \mathrm{G}_{2}\right)=1.23 \therefore \mathrm{D}\left(\mathrm{G}_{1}\right)>\mathrm{D}\left(\mathrm{G}_{1} \cup \mathrm{G}_{2}\right)$.

$\therefore$ Both $\mathrm{G}_{1}$ and $\mathrm{G}_{2}$ cannot be intense subgraphs of $\mathrm{G}_{1} \cup \mathrm{G}_{2}$. 


\section{APPLICATION OF EQUALLY BALANCED IF SUBGRAPHS IN CURRICULUM AND SYLLABUS FORMATION}

Curriculum is a complete course of study offered by a University; a syllabus is the outline of a single course. "Curriculum" refers either to all the courses offered by an educational institution or to the courses offered in a specific program. A syllabus is simply an outline, and the time line of a particular course. It will typically give a brief overview of the course objectives, course expectations, and list the reading assignments, and exam dates. The purpose of the syllabus is to allow the students to work their schedule for their own maximum efficiency and effectiveness. The curriculum and syllabus also provide the subjects and topics for a particular course, and prescribe the books to be studied. In designing the curriculum and syllabus for a course of study in higher education, weightage for the course content and knowledge gaining in all topics of study has to be balanced for the students to get maximum efficiency and effectiveness in the subject. Jillinda et al. [4] classified the knowledge sources into two types namely explicit and implicit knowledge. According to them sources of explicit knowledge may be exchanged during meetings or conference, in which a diversity of knowledge sources combines to shape a new and enhanced conception. Explicit knowledge may refer to such declarative knowledge that the holder may know to be true, but only through instruction that they are so. Explicit sources of knowledge are:

- Teaching aids, student performance records etc. from the faculty members

- Records and Materials collected by students

- Books and journals in the library

- Documents, reports and other administrative records from the admin personnel

- Audio and video records during conferences and seminars and others

Implicit knowledge is carried with us in the way we do things, as know-how. It can be revealed via processes, such as mentoring or through backand-forth, tailored explanations that occur in conversation. There are several sources of implicit knowledge in higher educational institutions. This implicit knowledge plays a key role in designing knowledge management systems, especially in designing decision making systems. The implicit knowledge sources in universities are:

- Faculty and visiting faculty members

- Administrative persons

- Students

- Industrial persons and eminent persons from the society.
If the curriculum and syllabus are not well planned and do not possess the proper balance of explicit and implicit knowledge, it leads the students to master a particular area and lag in some other areas since they may not have a proper balance of explicit and implicit knowledge. To avoid this mild balanced IFG comes as a boon which can be used as the most effective tool in balancing the explicit and implicit knowledge sources available and thereby making the syllabus and hence the whole curriculum most effective and efficient. Now let us consider a part of curriculum design for the post graduate mathematics students of some university. The curriculum for two years course includes major topics in mathematics such as, Modern Algebra (MA), Real Analysis (RA), Differential equations (DE), Operations research (OR), Complex Analysis (CA), Discrete Mathematics (DM), Topology (T), Queueing theory (QT), Analytic number theory (ANT), Functional analysis (FA) and Graph theory (GT).

While designing the syllabus for the course equal weightage has to be given to all the 11 topics. The available knowledge resources have to be equally balanced for better knowledge acquisition of the students. For this purpose, an IFG G:(V, E) can be generated with membership values indicating the availability of explicit knowledge sources within the university and nonmembership value indicating the maximum extent of availability of implicit knowledge sources from outside the university and is shown in the following graph. This can be made by using existing software which generates the percentage availability of explicit knowledge source and implicit knowledge source in any institution by feeding it with the available knowledge resources of the institution. With the help of portal, we can generate an IFG similar to the one given by us in the following example.

In this example we consider an IFG with vertex set of 11 papers for two years course of study for PG mathematics students of some institution and their membership value indicating percentage of faculty members with specialization and experience in the corresponding paper and nonmembership value indicating percentage of availability of visiting faculty members with specialization and experience in the corresponding paper. Also the membership and non-membership function of the edges indicates the percentage of subject experts with minimum 5 years of experience in handling the paper from the institution and from outside the institution respectively for both the pair of vertices. Adjacency matrix corresponding to IFG G:(V, E) in Fig: 7 is matrix corresponding to IFG G:(V, E) in Fig: 7 is as follows. 


\begin{tabular}{|c|c|c|c|c|c|c|}
\hline & DE & OR & QT & MA & RA & T \\
\hline DE & $(0.57,0.42)$ & $(0.356,0.315)$ & $(0,0)$ & $(0.285,0.315)$ & $(0,0)$ & $(0,0)$ \\
\hline OR & $(0.356,0.315)$ & $(0.475,0.42)$ & $(0.374,0.55)$ & $(0,0)$ & $(0.214,0.47)$ & $(0,0)$ \\
\hline QT & $(0,0)$ & $(0.374,0.55)$ & $(0.408,0.57)$ & $(0,0)$ & $(0,0)$ & $(0.306,0.428)$ \\
\hline MA & $(0.285,0.315)$ & $(0,0)$ & $(0,0)$ & $(0.38,0.315)$ & $(0.214,0.473)$ & $(0,0)$ \\
\hline RA & $(0,0)$ & $(0.214,0.47)$ & $(0,0)$ & $(0.214,0.473)$ & $(0.285,0.63)$ & $(0.255,0.6)$ \\
\hline T & $(0,0)$ & $(0,0)$ & $(0.306,0.428)$ & $(0,0)$ & $(0.255,0.6)$ & $(0.714,0.285)$ \\
\hline FA & $(0,0)$ & $(0,0)$ & $(0.23,0.428)$ & $(0,0)$ & $(0,0)$ & $(0.23,0.356)$ \\
\hline CA & $(0,0)$ & $(0,0)$ & $(0,0)$ & $(0,0)$ & $(0.285,0.63)$ & $(0,0)$ \\
\hline DM & $(0,0)$ & $(0,0)$ & $(0,0)$ & $(0,0)$ & $(0,0)$ & $(0,0)$ \\
\hline GT & $(0,0)$ & $(0,0)$ & $(0,0)$ & $(0,0)$ & $(0,0)$ & $(0,0)$ \\
\hline ANT & $(0,0)$ & $(0,0)$ & $(0,0)$ & $(0,0)$ & $(0,0)$ & $(0,0)$ \\
\hline
\end{tabular}

\begin{tabular}{|c|c|c|c|c|c|}
\hline & FA & CA & DM & GT & ANT \\
\hline DE & $(0,0)$ & $(0,0)$ & $(0,0)$ & $(0,0)$ & $(0,0)$ \\
\hline OR & $(0,0)$ & $(0,0)$ & $(0,0)$ & $(0,0)$ & $(0,0)$ \\
\hline QT & $(0.23,0.428)$ & $(0,0)$ & $(0,0)$ & $(0,0)$ & $(0,0)$ \\
\hline MA & $(0,0)$ & $(0,0)$ & $(0,0)$ & $(0,0)$ & $(0,0)$ \\
\hline RA & $(0,0)$ & $(0.285,0.63)$ & $(0,0)$ & $(0,0)$ & $(0,0)$ \\
\hline T & $(0.23,0.356)$ & $(0,0)$ & $(0,0)$ & $(0,0)$ & $(0.3,0.355)$ \\
\hline FA & $(0.306,0.475)$ & $(0,0)$ & $(0,0)$ & $(0,0)$ & $(0.232,0.414)$ \\
\hline CA & $(0,0)$ & $(0.309,0.552)$ & $(0.232,0.414)$ & $(0.309,0.276)$ & $(0,0)$ \\
\hline DM & $(0,0)$ & $(0.232,0.414)$ & $(0.412,0.276)$ & $(0.618,0.368)$ & $(0.386,0.276)$ \\
\hline GT & $(0,0)$ & $(0,0)$ & $(0.309,0.276)$ & $(0.386,0.276)$ & $(0.525,0.368)$ \\
\hline ANT & $(0.3,0.355)$ & $(0.232,0.414)$ & $(0,0)$ & & \\
\hline
\end{tabular}

Table: 4.1

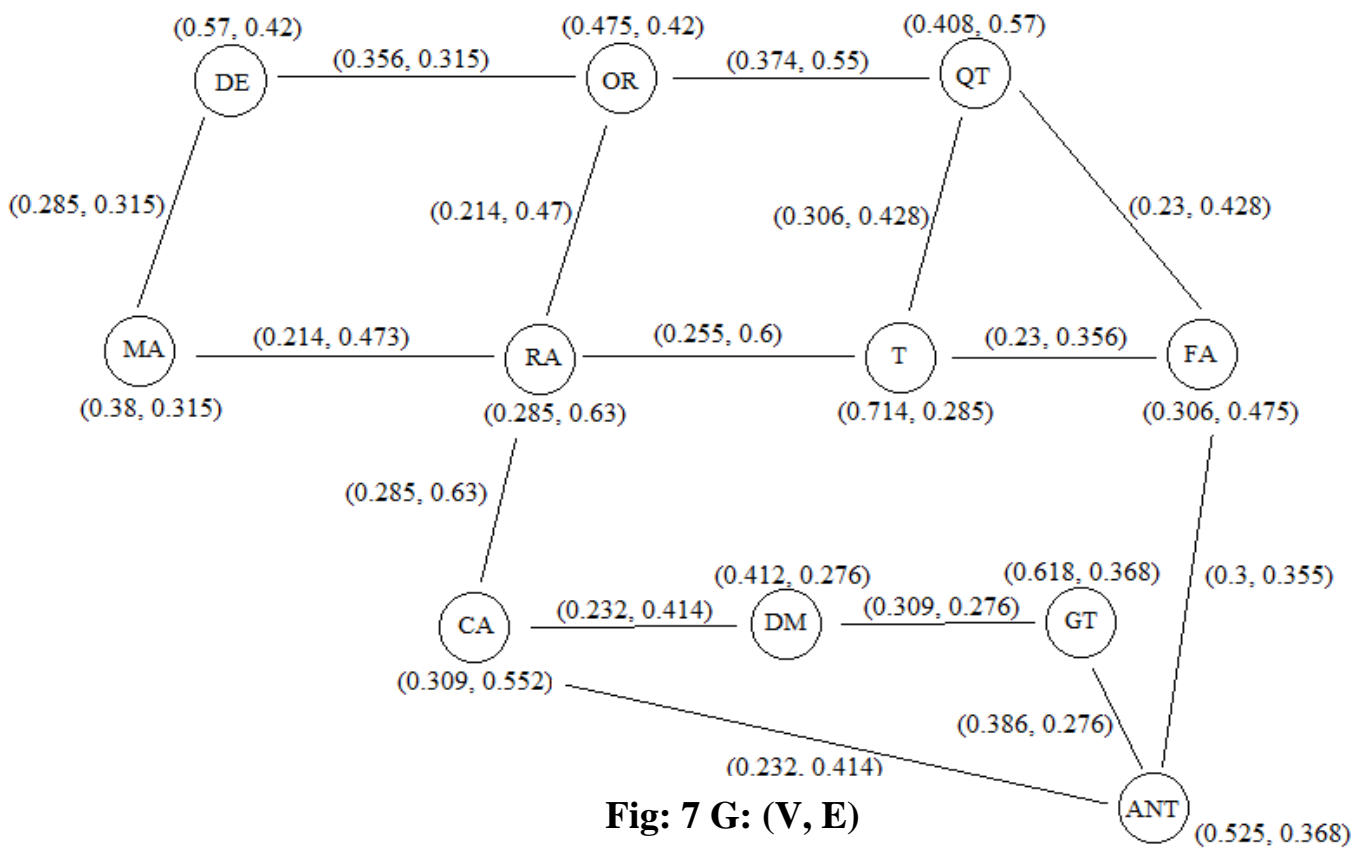


By the analysis of the above graph, we get $\mathrm{D}(\mathrm{G})=(1.6,1.6)$ with $\mathrm{D}\left(\mathrm{H}_{1}\right)=(1.5,1.5)$; where $\mathrm{H}_{1}=\{\mathrm{DE}, \mathrm{OR}, \mathrm{RA}, \mathrm{MA}\}, \mathrm{D}\left(\mathrm{H}_{2}\right)=(1.5,1.5)$; where $\mathrm{H}_{2}=\{\mathrm{QT}, \mathrm{T}, \mathrm{FA}\}$ and $\mathrm{D}\left(\mathrm{H}_{3}\right)=(1.5,1.5) ; \quad$ where $\mathrm{H}_{3}=\{\mathrm{CA}, \mathrm{DM}, \mathrm{GT}, \mathrm{ANT}\}$. Hence the subgraphs $\mathrm{H}_{1}, \mathrm{H}_{2}$ and $\mathrm{H}_{3}$ are found to be equally balanced subgraphs of G:(V, E). So it can be concluded that while designing the curriculum, the grouping of the topics for each summative assessment can be made in such a way that they form equally balanced IF subgraphs which will afford a good scope for knowledge management.

In the above example, it is obvious that while grouping the 11 papers for three consecutive summative assessment, it has to be done as $\mathrm{H}_{1}, \mathrm{H}_{2}$ and $\mathrm{H}_{3}$ which are equally balanced and therefore have well balanced knowledge sources (faculty and visiting faculty members) for all the three semesters.. As we go for other subgraphs, say $\mathrm{H}_{4}=\{\mathrm{OR}, \mathrm{QT}, \mathrm{T}, \mathrm{RA}\}, \mathrm{H}_{5}=\{\mathrm{RA}, \mathrm{CA}, \mathrm{FA}, \mathrm{ANT}\}$ etc they are feeble subgraphs of $\mathrm{G}$ and hence the students may face inadequate knowledge resource at some point of their curriculum. Hence while deciding the curriculum and syllabus mild balanced Intuitionistic Fuzzy graphs and equally balanced IF subgraphs can be used as an effective tool in deciding various parts in which knowledge management plays one of the vital role.

\section{CONCLUSION}

The concept of intense and feeble subgraphs can be extended to complement IFG and properties of intense and feeble subgraphs in complement graphs can be analyzed. Also as we have analyzed mild balanced IFG on union and sum of two IFG with one or more common vertices, the study can be extended to other operations such as product and composition graphs etc. As mild balanced IFG has vast applications such as enhancing strategies in management, improvement of performance in industrial sector etc a few real life examples can be analyzed and result oriented study can be predicted.

\section{REFERENCES}

[1]. Akram, M., Ashraf, A. and Sarwar, M. "Novel applications of intuitionistic fuzzy digraphs in decision support system." The scientific world journal (2014): 11 pages.
[2]. Akram, M., Karunambigai, M G., Palanivel, K. and Sivasankar, S. "Balanced bipolar fuzzy graphs." Journal of advanced research in pure mathematics Vol.6.No.4 (2014): 5871.

[3]. Anand kumar, N V. "Design and development of meta-model for knowledge management in higher education domain." Ph.D thesis, Anna University: July 2011.

[4]. Anthony Shannon and Atanassov, K. "On a generalization of intuitionistic fuzzy graphs." NIFS Vol.12.(1) (2006): 24-29.

[5]. Jillinda, J K., Karen, M V. and Sandra, L J. "Applying corporate knowledge management practices in higher education." Education quarterly No.4 (2000): 28-33.

[6]. Jun, Young Bae. "Intuitionistic fuzzy subsemigroups and subgroups associated by intuitionistic fuzzy graphs." Commun. Korean Math. Soc. Vol.21.No.3 (2006): 587593.

[7]. Karunambigai, M G., Sivasankar, S. and Palanivel, K. "Properties of balanced intuitionistic fuzzy graph." International journal of research in science Vol.1.No.1 (2014): 01-05.

[8]. Karunambigai, M G., Akram, M., Sivasankar, S. and Palanivel, K. "Balanced intuitionistic fuzzy graphs." Applied mathematical sciences Vol.7.No.51 (2013): 2501-2514.

[9]. Mordeson, J N. and Nair, P S. "Fuzzy graphs and fuzzy hypergraphs." Physica 2nd edition (1998-2001).

[10]. Nivethana, V. and Parvathi, A. "Arc analysis in intuitionistic fuzzy graphs and its application." Notes on intuitionistic fuzzy sets Vol.22.No.1 (2016): 53-62.

[11]. Nivethana, V. and Parvathi, A. "Extended regular intuitionistic fuzzy graphs." IOSR Journal of mathematics Vol.12, Issue 4.No.3 (2016): 06-12.

[12]. Nivethana, V. and Parvathi, A. "On complement of Intuitionistic fuzzy graphs." International journal of computational and applied mathematics Vol.10.(1) (2015): 1726. 
[13]. Parvathi, R., Karunambigai, M G. and Atanassov, K T. "Operations on Intuitionistic fuzzy graphs." Fuzz-IEEE (2009): 1396-1401.

[14]. Rucinski, A. and Viince, A. "The solution to an external problem on balanced extensions of graphs." Journalof graph theory Vol.17 (1993): 417-431.

[15]. Wu, S Y. "The Composition of fuzzy digraphs." Journal of research in education sciences Vol.31 (1986): 603-628. 